\title{
Childhood Obesity: How Engaging Parents of Children with Elevated Body Mass Index in Positive Dietary and Lifestyle Education in Pediatric Primary Care Improved Parental Role Modeling Practices within the Home
}

\author{
Gwendolyn Miller ${ }^{1}$, Aimee C. Vael ${ }^{1 *}$, Kimberly A. Hires ${ }^{2}$ Lee H. Eades ${ }^{2}$ \\ ${ }^{1}$ School of Nursing, Columbus State University 4225 University Ave, Columbus Georgia, 31907, USA \\ ${ }^{2}$ Byrdine F. Lewis School of Nursing and Health Professions, Georgia State University, PO Box 4019, Atlanta GA, 30302-4019, USA
}

\begin{abstract}
Article Details
Article Type: Research Article

Received date: $26^{\text {th }}$ July, 2017

Accepted date: $17^{\text {th }}$ February, 2018

Published date: $19^{\text {th }}$ March, 2018

"Corresponding Author: Aimee C. Vael, Department of Nursing, Columbus State University, Columbus Georgia, 31907, USA. E-mail: vael_aimee@columbusstate.edu

Citation: Miller G, Vael AC, Hires KA, Eades HL (2018) Childhood Obesity: How Engaging Parents of Children with

Elevated Body Mass Index in Positive Dietary and Lifestyle Education in Pediatric Primary Care Improved Parental Role Modeling Practices within the Home. J Comp Nurs Res Care 3: 124. doi: https://doi.org/10.33790/jenrc1100124.

Copyright: $(2018$, This is an open-access article distributed under the terms of the Creative Commons Attribution License 4.0 , which permits unrestricted use, distribution, and reproduction in any medium, provided the original author and source are credited.
\end{abstract}

\begin{abstract}
The purpose of the quality improvement (QI) project was to provide parents nutritional education of recommended feeding practices as a means of encouraging parents to incorporate healthy parental role modeling behavior at home and reduce pediatric body mass index (BMI). The plan-do-study-act was the chosen methodology applied to initiate a practice change within the current treatment of childhood obesity in the outpatient pediatric setting $[1,2]$. There was a total of 9 parent/child dyad participants who completed the study. The inclusionary criteria for the study was the child was 2-5 years old, with a body mass index (BMI) greater than or equal to $85 \%$ according to the pediatric growth curve with accompanied parents/ guardians that was able to give consent. The study demonstrated that there was a statistically significant difference in the pre-survey scores $(\mathrm{M}=19.00, \mathrm{SD}=5.39)$ and the post-survey scores $(\mathrm{M}=16.44$, $\mathrm{SD}=3.32) ; \mathrm{t}(8)=2.34, \mathrm{p}=.048$; clarifying that lower/decreased survey scores demonstrated an improvement in parental knowledge. There was not a significant difference be- tween the pre-educational BMI $(\mathrm{M}=18.27, \mathrm{SD}=.75)$ and the post-educational BMI $(\mathrm{M}=18.39$, $\mathrm{SD}=1.16$ ) of study participants; $\mathrm{t}(8)=-.35, \mathrm{p}=.734$. This study used the Parental Role Model Assessment tool to compare the pre-interventional parental role modeling scores to the post-interventional role modeling scores within the pediatric home. The quality improvement (QI) team determined that the post interventional Parental Role Model Assess- ment scores decreased which suggested that the educationl intervention delivered by the pediatric provider on positive parental role modeling was retained and modeled by the parents within the pediatric home over a 3 month period. The team concludes that enhancing standards of practice within the pediatric primary care setting to allow for improving parental nutritional/ lifestyle knowledge deficits and providing education to strengthen positive parental role modeling will act to enhance quality-health outcomes within the pediatric obese/overweight population.
\end{abstract}

Keywords: Parents (PR), Preschoolers (PS) and Obesity (OB)

\section{Introduction}

Childhood obesity is a public health crisis that increases negative health outcomes and rising cost within the American health care system $[2,3]$. Obesity leads health care providers, public health officials, and communi- ties to search for answers to reverse the advancement of the disease and its co-morbid effects [2-5]. Increasing parental nutrition knowledge and encouraging parental involvement in pediatric weight loss treatment plans in the primary care setting is one solution to address the childhood obesity epidemic [68]. Implementation of interactive, educational, family-centered interventions within primary care encourages parental engagement in pediatric weight loss treatment plans to increase the success in BMI reduction $[9,10]$. Parents are influential in food choices and exercise habits, but have limited interventional focus within current pediatric practice [11, 12]. The project determined if implementing a parent focused healthy lifestyle, interactive educational class is an effective intervention for obesity treatment within a pediatric outpatient primary care setting.

The purpose of the project was to provide parents nutritional education of recommended feeding practices as a means of encouraging parents to incorporate healthy parental role modeling behavior and reduce pediatric BMI. This project aimed to empower the parents by providing knowledge of nutritional approaches that can be imple- mented in the home to decrease pediatric BMI. The objectives of this project were as follows:

1. Parents will have a deeper cognizance of early comorbid/mortality rates and the importance of maintaining a healthy childhood BMI;

2. Parents will incorporate knowledge of recommended nutritional practices at home;

3. Parents will have a lower post-survey nutritional scores when compared to pre-survey scores to validate nutritional knowledge retention;

4. Parents will implement the knowledge gained and introduce the weight loss treatment plan in the home to reduce pediatric BMI;

5. There will be a notable BMI reduction of $0.1-1.0$ pound per month after parental education secession. 


\section{Background and Signficance}

Childhood obesity is an area of concentrated reform by The World Organizations (WHO), The Centers for Disease Control (CDC), and The American Academy of Pediatrics [13-16]. Fortytwo million children worldwide under the age of five years are clinically overweight or obese, and, therefore, the WHO described this epidemic as the time of "globesity"[16]. In addition to the world obesity rates, $17 \%$ of American youth have a clinical diagnosis of obesity [17-19]. Georgia is the nineteenth leading state in childhood obesity; one in three children within the state of Georgia has a diagnosis of overweight or obesity [20,21].

The recent public attention on childhood obesity is an attempt to recognize the epidemic and prevent the negative physical and emotional impact that obesity places on youth $[2,19]$. Lifelong physical and mental effects of early obesity prevents the achievment and maintenance of optimal health in the pediatric patient $[13,17,19$, 22]. Childhood obesity increases the risk for the development of health conditions that affect musculoskeletal, neurological, hepatic, gallbladder, cardiac and kidney systems [17]. Obesity places children under chronic physiological and psychologic stress [2, 17, 22]. Congestive heart failure, diabetes mellitus type II, asthma, arthritis, and end-stage renal disease are physiologic conditions that may result from the early presence of obeseogenic environments $[2,17$, 19]. Obeseogenic environments are primarily parental/guardian controlled situations in a child's life where there is frequent subjection to behaviors such as overnutrition, sedentary lifestyles, and insufficient healthy food consumption [23, 24]. Psychological effects include stress, depression, isolation, anxiety, and decreased social functioning [2, 22]. The presence and advancement of progressive conditions cripple the obese population's quality and longevity of life $[2,25]$.

The significant impact on nursing, advanced practice providers, and healthcare is the increased complexity of care $[6,14,15]$. Treatment efforts are not exclusive to dietary and exercise interventions, but consists of mul- tifactorial aims [3, 11]. Childhood obesity treatment plans are tailored towards multi-causative effects such as socioeconomic, economic, psychological, demographic, and genetic ramifications $[3,9,11]$. Behavioral change therapies and resources in successful obesity treatment are complicated and time consuming for one healthcare provider, but are necessary to target the various parts of the child to reduce and maintain a healthy BMI $[14,15,26]$. Obesity's economic impact on the American healthcare system is contributing to a spending of $\$ 150$ billion ciated disorders with $\$ 60$ billion produced from Medicaid and Medicare services [27].

With the rise in the number of preschoolers affected with obesity, the intended age for pediatric care to initiate obesity prevention, treatment, and management modifications should be younger [24, $28,29]$. An elevated BMI for preschoolers increases the risk for the development of adult obesity [14, 15, 28-30]. Preschoolers who are overweight or obese are five times more at risk than normal weight children to carry obesity into adulthood $[31,32]$.

The phenomenon of adiposity rebound (AR) determines preschoolers as the focal point in weight loss initiatives $[14,15,30]$. AR is the second predicted weight gain progression in a child's life predicted to occur between five and six years old when a child experiences an increase in fat cell production accompanies a rise in BMI [13, 30,33]. However, children who reach rebound at a younger age of 4.8 are at an increased risk for obesity later in life [14, 28, 30, 33].

The second reason two to five-year-olds are the age for obesity prevention is the amount of control that parents have within this age group [14, 24, 34]. Parents of preschoolers can institute healthy home lifestyle practices such as increasing exposure to fruits and vegetables, encouraging family mealtime, preparing foods with healthier oils/ spices, and increasing the times of re-exposure to foods [5, 14, 24].
Preschool children have limited exposure to the outside world without parental presence; if parents institute nutritional environmental control, then the child's submergence into a healthy living situation should reflect a healthy preschooler BMI [9, 14, 24].

\section{Obesity Prevention in Pediatric Primary Care \\ Pediatric Primary Care as Setting for Obesity Reform}

The primary care pediatric provider, starting with prenatal visits and contining throughout childhood, has an opportunity to deliver family-centered nutrition information to reduce the prevalence of pediatric obesity $[2,14,35,36]$. The pediatric provider has the opportunity to assess BMI with scheduled well visits and exams [12, $15,34,37]$. Pediatric providers develop a trusted relationship that enables the discussion of sensitive family issues such as obesity and weight loss [12, 15, 34, 37].

\section{Parental Educational Intervention}

The majority of children with elevated BMIs have parents with elevated BMIs $[2,14,15]$. Positive parental nutritional role modeling in the obese/overweight pediatric patient is an effective lifestyle change for the family unit and the pediatric patient $[2,14,35,36]$. However, time constraints and decreased reimbursement rates for pediatric providers to deliver the needed parental educational or counseling sessions hinder parents from an indepth nutritional discussion with the pediatric provider [38-40]. This results in a parental nutritional knowledge deficit and continued unhealthy parental feeding practices causing persistent increases in pediatric BMI $[6,14,15,24]$.

Primary care educational interventions that are hands-on with increased parental involvement demonstrates a reduction in childhood obesity/BMI in two to five-year-olds [6, 41]. Handson educational interventions that explore parental behaviors of goal setting, self-behavioral strategies, and social support increase the success of pediatric weight loss [23, 42]. It is vital to identify a parental nutritional knowledge deficit and address the issue with a hands-on interactive educational intervention. Incorporating an educational intervention will increase parental engagement in positive role modeling and reduce pediatric BMI [23, 41].

\section{Parental Behaviors to Target and Enhance Nutritional Role Modeling}

\section{Pressure feeds and overfeeding}

Parental behaviors causing childhood obesity are pressure feeds and overfeeding. Pressure feeding occurs when an parent/guardian attempts to sooth or calm an infant/child with food without the physiologic presence of hunger. A parental action of misinterpreting infant/child behavioral cues that potentiates the behavior of overfeeding [24, 43]. Infancy and early toddlers have limited vocabulary usage, which makes it difficult for parents to recognize cries such as hunger cries, boredom cries, and fatigued cries [14, $15,24,43]$. Parents who are unable to soothe infant/toddler and misinterpret signal cues need primary provider education to reduce pressure feeding and overfeeding [14, 24, 43, 44]. Positive parental role model within the home with the introduction of strategies to soothe with pacifier, play, and sleep are beneficial to obtain child comfort and align with pediatric obesity prevention [14, 15, 24, 43].

\section{Controlling table manners}

The presence of controlling parental feeding practices at meal time is a parental be- havior that is linked to childhood obesity [24, 45]. Controlling feeding styles is the parenteral behavior of rewarding or punishing a child who does not eat all of their meal. Reduction in this parenteral behavior has shown to prevent obesity. [24]. Pediatric provider education that informs parents of reducing controlling behaviors at mealtime will assist the parents with positive role modeling to increase success rates of pediatric BMI reduction [14, $15,24,45]$. 


\section{Limit family television}

Television viewing under two hours a day is necessary for the pediatric population to maintain a healthy $\operatorname{BMI}[6,14,15,46]$. Television viewed during meal time increases meal consumption, caloric intake, and portion size [24]. Sixty percent of parents reported that family screen time is more than 2 hours a day; an increase in family television time increases the total BMI of the family [46]. Parental effort to limit television within the home decreases family adiposity and improves positive parental role modeling to obtain pediatric weight-loss goals [46].

\section{Increase the reintroduction of foods}

Reduced food reintroduction in children who display an initial dislike to the food is a maladaptive parental behavior [14, 15, 24]. Parents need education to continue reintroduction of foods up to ten to fifteen times to determine the child's flavor preference $[14,15,24]$. Children who are three years old with increased exposure to fruits and vegetables continue in childhood to consume healthy foods [47]. The premature parental assumption of disaffinity toward foods like fruits and vegetables will decrease pediatric consumption of healthy foods and promote obesogenic childhood behaviors [14, 15, 24, 48].

\section{Increase family fruit and vegetable consumption}

Pediatric consumption of fruits and vegetables is linked to parental ingestion; children eat what parents eat [45, 49]. Parents that eat 3.55 cups of vegetables a day have children who consume increased amounts of fruits and vegetables [5]. The traditional household is arranged with mothers as the typical meal preparer; a mother's comfort, past exposure, and self-efficacy with fruit and vegetable within the home determines the use of the foods for wholesome family ingestion [5, 45, 49]. A father's preference toward recipes prepared with fruits and vegetables effects the mother's use of the foods in the house. Limited paternal affinity towards fruits and vegetables can prohibit family exposure to healthy foods within the household [5, 45, 49].

\section{Control portion sizes}

Preparation of large portions of food is a maladaptive parental behavior that has contributed to childhood obesity. In young children, portion sizes are determined from parents [50,51]. Parents that offer larger portion sizes often do not know the correct serving size per age group and consume larger portions sizes themselves. Children respond to larger portions of food with an increased bite size to increase food consumption. Excessive calorie ingestion over the span of childhood increases in childhood BMI [50].

\section{Physical activity}

Exercise is paramount to pediatric health; it helps to prevent physical and psychological stresses to assist children with healthy living $[14,15,52]$. Children need to be active at least 60 minutes a day to maintain optimal health. Children's activity level is mirrored by the activity level of the parents; parents who exercise have children who exercise and parents who live sedentary lifestyles have children who live sedentary lifestyles [14, 15, 41, 52]. Parental involvement in lifestyle intervention programs that assist the family towards developing a daily exercise routine show a significant decrease in pediatric BMI reduction [3, 41].

\section{Methodology}

Plan-do-study-act (PDSA) was the study design chosen to initiate a QI practice change within the current treat- ment of childhood obesity in the outpatient pediatric setting [1]. The study was described according to CON- SORT 2010 because this study is an intervention study. The PDSA is devised of four steps listed as follows: 1. Plan, 2. Do, 3. Study, 4. Act $[1,53]$.

\section{Plan}

A plan for the QI project is presented in the form of an aim statement $[1,54]$. The aims of the QI project were: By March 2017, $80 \%$ of parents of overweight/obese children between the ages of two to five years with a BMI greater than or equal to $85 \%$ will have a summation improvement in post-survey role modeling scores when compared to the pre-survey scores; (2) By March 2017, there will be a BMI reduction of 0.1-1.0 pound per month for the overweight/ obese pediatric patient.

\section{Setting}

The site for the study was an urban outpatient pediatric setting located along the Georgia/Alabama border. The city has a total population of 200,579, of which, $7.4 \%$ are under the age of five. The city's ethnic demographics are Caucasians $46.3 \%$, African American 45.5\%, Hispanic or Latino 6.4\%, and Asian 2.2\%. The median income is $\$ 42,306$ [55]. The investigator was the only staff at the chosen setting that participated in the QI project. The urban outpatient pediatric setting contains approximately 1800 patients shared between four healthcare providers-three nurse practitioners and one medical doctor. Each provider in the chosen urban outpatient pediatric seeting evaluates approximately 22 patients daily. The practice evaluates sick and well pediatric patients from newborn to nineteen years old. The medical practice building consists of six examination rooms with accompanied office space (I. Basilio, personal communication, January, 13. 2016).

\section{Subjects}

Inclusion criteria for the child was 2-5 years old, with a BMI greater than or equal to $85 \%$ according to the pediatric growth curve with accompanied parents/guardians able to given constant. Inclusion criteria for the parent/guardian were the presence of at least one child between two to five years old with a BMI greater than or equal to $85 \%$ according to the pediatric growth curve. In addition, the parents/ guardian had to be at least 18 years of age, English speaking, and able to provide voluntary consent for participation in the study. The exclusion criteria for the child was any age other than 2-5 years old with a BMI less than $85 \%$ according to the pediatric growth curve. In addition, children and/or parents were excluded from the study if the parent/guardian did not give voluntary consent to the study. Parents/guardians were excluded from the study if they were younger than 18 years of age, did not speak English, and were not able to provide voluntary consent for participation in the study. The intent of exclusion of subjects was to focus efforts on parents of children with BMIs greater than $85 \%$.

\section{Sampling method}

Convenience sampling was used to obtain participants for this project. The facility's EMR was reviewed through the months of August-November, 2016 to determine if any participants were scheduled to come to the pediatric outpatient office the following day of study implementation. In this review, the weight, height, and BMI were assessed per the patient's growth curve to screen for potential participants before their arrival to the office.

\section{Process of accruing participants}

Patients were invited to participate in the project upon the dyad's arrival to the office. Having evaluated if the prospective subjects met some inclusionary criteria the day prior, the investigator was equipped with a sealed envelopes containing the consent form (Appendix A) and a pre-role modeling survey (Ap- pendix B) for the parents upon the parent/child dyad's arrival for the scheduled well-child visit [56]. This information was given to the parent while they awaited examination by the health care provider, which allowed ample time for parental consideration, review, and questioning. After the consents were signed, the parents/guardian were provided with a copy and the originals were kept in a locked file cabinet in an office for which the study investigator had the key.

\section{The total number of subjects}

A sample size of 100 parents and children was the upper limit 
of the sample. This was determined by a review of office visits between January through March by those that fit the inclusion criteria. The review concluded that 100 patients within the study parameters were seen during this time period. A total of 200 parent/ child dyad participants was the total number of participants selected for this study.

\section{Tools}

The data in QI project was adpated from the Strong4Life Role Model Assessment tool [56]. The reliablity and validity of the tool was not necessary to identify for the QI project. The QI project negated that the chosen tool was to provide a Needs Assessement; therefore, a pilot tool was chosen to suit the requirements of this project. For the purposes of the QI project the chosen tool was reidentified as the Parental Role Model Assessment tool (Appendix B) [56]. In addition to the Parental Role Model Assessment tool, the QI project also used the pediatric growth chart (Appendix C) [57].

\section{Do}

\section{Implementing the intervention}

Once the preliminary decisions were made by the QI committee, approval from the Institutional Review Board was obtained to start the "Do" phase of the project. The "Do" phase of the QI project is where the investigator was able to implement the intervention, the interactive educational session, into the clinical setting to determine if it improved the quality in pediatric obesity care [1].

\section{Project procedures, intervention, and operational plan}

After obtaining consent, the parent (guardian)/child dyad was invited to join the QI project. The well-child exam was completed by the health care provider. The pre-survey was administered in paper/ pencil format during the beginning of the study. Upon completion of the pre-survey, the intervention was delivered by the investigator, a family nurse practitioner who has practiced pediatric medicine for three years. An interactive educational session was recommended by best practice and selected as the intervention chosen for the QI project. The educational session lasted approximately five to ten minutes and focused on increasing parental knowledge of the benefits of healthy parental role modeling in the treatment of childhood obesity. The intervention allowed the discussion of parental ways to enhance positive role modeling and educated the parents on the following subjects: reintroduction of foods, limit controlling table manners, portion control, participate in physical activity, and increased fruit and vegetable consumption. The participants were counseled that follow-up visit was in three months. Parents were notified one week prior to the return visit they would receive a call to schedule their follow-up visit. Parents were instructed that the subsequent visit was free of charge and the investigator was the only provider to be seen at that time. Once the follow-up was scheduled, the parent/child dyads came to the office to complete the post-role survey and assessment of the child's BMI.

\section{Study}

Participants were asked to fill out 11 questions from the Parental Role Model Assessment tool for the pre and post survey. The survey was a Likert scale formulated to determine parental role modeling habits at home. Three answers were possible for each statement. The answer always/most of the time was given 1 point, about half the time was given 2 points, and not at all 2 points, and very little/not at all was given 3 points. The answer choice very little was given the highest number because it was the answer that demonstrated the most inadequate presence parental role modeling in the home.

The points were tabulated with the lower scores indicating healthier lifestyle, and ranged from 11-33. It is impo- rant to realize that the lower the score the healthier the parents were role modeling; determining that a lower score was the desired outcome for the postsurveys. The format of the results asked participants to mark their answers with a pencil or pen mark.

After participant completion of the survey, the Parental Role Model Assessment tool was tallied to a numerical value. The summation of the numerical values for both pre and post surveys were compared when the research was finalized.

\section{Results}

Thirteen parent/child dyads agreed to participate in the QI project, completed the pre-survey, and received the educational intervention. Sixty nine percent $(n=9)$ of the participants finished the research project in its entirety. The mean age of the children who participated in the project was 2.9 years old $(\mathrm{SD}=0.5)$. A paired t-test was chosen for the QI project to compare two population means where you have two samples in which observations in one sample can be paired with observations in the other sample. The data to be compared in this study was the parental survey and child's BMI before and after the intervention. There was a statistically significant differ- ence in the pre-survey scores $(\mathrm{M}=19.00, \mathrm{SD}=5.39)$ and the post-survey scores $(\mathrm{M}=16.44, \mathrm{SD}=3.32) ; \mathrm{t}(8)=2.34, \mathrm{p}=.048$; clarifying that lower/ decreased survey scores demonstrated an improvement in parental knowledge. There was not a significant difference between the preeducational BMI $(\mathrm{M}=18.27, \mathrm{SD}=.75)$ and the post-educa- tional $\mathrm{BMI}$ $(\mathrm{M}=18.39, \mathrm{SD}=1.16)$ of study participants; $\mathrm{t}(8)=-.35, \mathrm{p}=.734$. Refer to (Appendix E) for graphical representation of data.

\section{Discussion}

This QI project aimed to incorporate a family-centered treatment plan by instituting an interactive, educational program focused on positive parental role modeling, the suggested intervention to decrease pediatric BMI in the chosen urban, outpatient pediatric setting. The primary objectives would qualify as met, if the data survey scores accompanied with a reduction in the child's BMI after three months. The findings from this QI project demonstrated that using an interactive educational program on importance of parental role modeling improved parental knowledge retention, but had no statistical significance in reducing pediatric BMI.

With the recent rise in obesity and its accompanied comorbid effects on pediatric health, a change in obesity care needs to occur to improve the quality of care provided to the pediatric obese/overweight patient $[6,7,44]$. In addition, obesity expansion in the preschool age group, increased predisposition of overweight/obese preschool- ers towards adult obesity, and preschool parents maintaining primary control over food choices; validates that younger age obesity efforts in primary care are needed [14, 24, 28, 30].

Parents are the catalyst for dietary changes within the pediatric family, [41, 49]. Empowering parents to facil- itate weight loss reduction plans in the home is essential to dietary management; without parental involvement in BMI reduction plans medical efforts will be futile $[2,14,15,24]$. In addition, overweight/obese children have parents who are overweight/obese [2, 14, 15]. Pediatric providers need to assess for parental nutritional inad- equacies, and target education efforts towards the deficits to reduce pediatric BMI. However, in the pediatric outpatient setting the absence or presence of parental role modeling is not assessed [14, 15, 23].

Implementation of the pretest before the interactive educational intervention allowed the investigator-a pediatric primary care provider- to assess for maladaptive parental role modeling in the pediatric home. Through discussion of current parental dietary and lifestyle habits, role modeling deficiencies are recognized and discussed to assist the parents in eliminating the areas of obesogenic potential for the entire family $[2,10,11,24]$. Areas discussed in the educational intervention were the reintroduction of foods, limiting controlling table manners, portion control, participate in physical activity, and increased fruit and vegetable consumption. The topics were chosen because of the relevance to the preschool age group and the areas susceptibility for contributing to maladaptive parental role 
modeling $[5,14,15,24,43,58]$.

An expected finding was that the post-survey scores were lower than the pre-survey scores. The lower post-survey scores indicate that the information provided to the parents during the educational intervention was retained and implemented in the home three months after initiation of the QI project. Determining, that the educational intervention was a valid intervention when aiming to teach the parents of obese/overweight preschoolers how to improve upon their positive nutritional and lifestyle role modeling in the home. It was identified that using an interactive, educational intervention will increase parental engagement in positive role modeling behaviors in the pediatric home [41].

An unexpected finding was that there was not a significant difference between the pre-educational BMI and the post-educational BMI. With the national increase in pediatric BMI, the aim of the QI was to implement an intervention to decrease pediatric BMI. However, with the limitations of the study- such as the three-month project period and obesity's multi-causative effects; the QI team recognized that BMI reduction could be difficult to at- tain. Suggesting, that a longer implementation cycle with an adjustment in the clinical question to include other obesity risk factors- besides parents- could potentiate a successful BMI reduction practice change. Treatment efforts consist of multifactorial aims with efforts towards improving all unhealthy lifestyle habits to disrupt the cycle of obesogenic behavior [3, 11].

\section{Limitations}

The first limitations of the study are contributory to the project design. The first limitation was the subject size. A sample of size of 13 determines that the project is not generalizable to the entire population [59]. The second limitation was the pre-test/post-test study design. A methodology created with the administration of a post-test three months after the pre-test could have reduced follow-up success. In addition, a post-test design would have more accurately validated knowledge retention if administration of the post-test persisted at six months, twelve months, and eighteen month intervals. However, there was a short time-period of three months per participant, and six months per entire project and that could have limited the research results. The months chosen were October, November, December, and January to conduct the study. These holiday months are often the busiest times of the year for families- suggesting that choosing another time of year to implement the project could have increased participation/follow-up success.

Outside of the study design, another limitation noted was the presence of a pre-existing parental perception of a healthy childhood BMI and body stature. Many parents have the misperception of childhood obesity as "just a phase" or "we are big boned in our family"; choosing to disregard weight loss counsel, making it difficult for healthcare providers to implement successful weight loss treatment plans in the pediatric home [36]. Pre-existing perception concerning pediatric obesity was present in this QI project, as well, and it affected the available sample size. For example, of the 13 parent/child dyads that participated, 16 parent/child dyads acknowledged refusal based on pre-existing perceptions; suggesting the child's stature "is not obese/overweight", even though the BMI informed otherwise.

The last limitation is that the causation of obesity is multifactorial. The multiple causations of obesity can impede treatment efforts and reduce success if the provider does not target all avenues of the disease $[2,14,15]$. The risk factors for childhood obesity are psychosocial, demographics, genetic, behavioral, and environmental $[2,14,15]$. The QI project was limited because it instituted a change towards one area of obesity- the parents. This action could have limited the project results; noting that targeting another risk factor, such as demographics, could have expanded results to include eliciting a reduction in pediatric BMI.

\section{Implications for Practice}

Implementation of a family-centered intervention such as the parental educational class could improve the quality of practice in preschool obesity care in an urban, outpatient pediatric setting. Nevertheless, due to the projects small samples size, the results were not generalizable to the entire population, and should not be implemented on a system-wide scale without conducting further research. With high patient volumes restricting the provider-patient time and decreased reimbursement for preventative services, the opportunity for the providers to discuss educational topics such as obesity are limited [38-40]. Despite the limited time in pediatric primary care, the QI project enabled an increased availability for a pediatric provider to implicate effective positive parental role modeling education in the practice environment to initiate weightloss treatment plans in the home of the pediatric patient.

\section{Conclusion}

In conclusion, the QI project aimed to provide parents nutritional education of recommended feeding practices to encourage the incorporation of healthy parental role modeling behavior in the pediatric home to reduce child- hood BMI. This study used the Parental Role Model Assessment tool to compare the preinterventional parental role modeling to the post-interventional role modeling within the pediatric home. The QI team determined that post interventional Parental Role Model Assessment scores decreased which suggested that the educationl intervention delivered by the pediatric provider on positive parental role modeling was retained and modeled by the parents within the pediatric home over a 3 month period.

The identification of poor parental role modeling is essential for pediatric providers to assess to improve paren- tal nutritional and dietary lifestyle deficiencies [23, 41]. Without the ability to assess a parent's baseline knowl- edge of diet and nutrition pediatric primary care's weight reduction and treatment plans are often couterproductive with the household continuing the same negative behaviors [23]. However, use of the Parental Role Model Assessment tool within this QI project exposed maladaptive parental role modeling. Once acknowledged, the pediatric provider was able to tailor education to reduce the parental knowledge deficiencies surrounding the importance of initiating positive parental rolemodeling in the home to reduce pediatric BMI. The QI team ac- knowledges that although this study did not demonstrate a decrease in pediatric BMI, due to the defined lim-itations of the study; the achievement of positive parental role modeling in the pediatric home is essential to a successful pediatric weight loss treatment plan. The team concludes that enhancing standards of practice within the pediatric primary care setting to allow for improving parental nutritional/lifestyle knowledge deficits and providing education to strengthen positive parental role modeling will act to enhance quality-health outcomes within the pediatric obese/overweight population.

\section{References}

1. Gillam S, Siriwardena AN (2013) Frameworks for improvement: Clinical audit, the plan-do-study-act cycle and significant event audit. Qual Primary Care 21: 123-130.

2. Hopkins KF, De Cristofaro C, L. Elliott (2011) How can primary care providers manage pediatric obesity in the real world? J Am Aca Nurs Practitioners 23: 278-288.

3. Hunter HL, Steele RG, Steele MM (2008) Family-based treatment for pediatric overweight: Parental weight loss as a predictor of children's treatment success. Child Health Care 37: $112-125$

4. Waters E, Summerbell CD, Edmunds L, Kelly SAM, Brown T, et al. (2012) Interventions for preventing obesity in children. Cochrane Datbase of Systematic Reviews 44: 36-45. 
5. Wenrich TR, Brown JL, Wilson TR, Lengerich JE (2012) Impact of a community-based intervention on serving and intake of vegetables among low-income, rural appalachian families. J Nutr Educ Behav 44: 36-45.

6. Boles RE, Scharf C, Stark LJ (2010) Developing a treatment program for obesity in preschool-age children: Preliminary data. Child Health Care 39: 34-58

7. National Guideline Clearing house (2013) Prevention and management of obesity for children and adolescents.

8. Sargent GM, Pilotto LS, Baur LA (2010) Components of primary care interventions to treat childhood overweight and obesity: A systematic review of effect. Int Assoc for the Stud of Obes 12: 219-235.

9. Hingle MD, O’Conner TM, Baranowski T (2010) Parental involvement in interventions to improve child dietary intake: Systematic review. Preventative Medicine,. 51: 103-111.

10. Myoungock J, Whittemore R (2015) The family management style framework for families of children with obesity. J Theory Construction \& Testing 19: 5-14

11. Thompson ME (2010) Parental feeding and childhood obesity in preschool-age children: Recent findings from the literature. Issues in Comprehensive Pediatric Nursing 33: 205-267

12. Young RF, Schwartz KL, Monsur JC, West P, Neale AV (2008) Primary care of overweight children: The importance of parent weight and attitudes about overweight. J Am Board Fam Med 21(4): 361-363

13. Center for Disease Control and Prevention [CDC] (2009) Obesity among low-income preschool children.

14. Hassink S, Elk Grove IL (2006) A Parent's Guide to Childhood Obesity:A Roadmap to Health, The American Academy of Pediatrics.

15. Hassink S, Elk Grove IL (2007) Pediatric Obesity: Prevention, Intervention, and Treatment Strategies for Primary Care. The American Academy of Pediatrics. The American Academy of Pediatrics.

16. The World Health Organization [WHO] (2015) Obesity and overweight.

17. Eisenmann JC (2011) Assessment of obese children and adolescents: A survey of pediatric obesity-management programs. Pediatrics 128: 51-58.

18. Gollust SE, Kite HA, Benning SJ, Callanan RA, Weisman SR, et al. (2014) Use of research evidence in state policymaking for childhood obesity prevention in Minnesota. Am J Pub Health 104: 1894-1900.

19. Ogden CL, Carroll MD, Kit BK, Flegal KM (1999-2012) Prevalence of obesity and trends in body mass index among us children and adolescents. JAm Med Assoc 307: 483-490.

20. Alliance for a Healthier Generation (2016).

21. The State of Obesity Better Policies for a Healthier America (2016) Obesity rates and trends.

22. Wilson SM, Sato AF (2014) Stress and pediatric obesity: What we know and where to go. J Int Soc Investigat Stress 30: 91102.

23. Boles RE, Yun L, Hambidge SJ, Davidson A (2015) Influencing the home food and activity environment of families of preschool children receiving home-based treatment for obesity. Clinical Pediatrics 54: 1387-1390.

24. Anzman SL, Rollins BY, Birch LL (2010) Parental influence on children's early eating environments and obesity risk: Implications for prevention. Int J Obes 34: 1116-1124.
25. Saviñon C, Taylor JS, Canty-Mitchell J, Canty-Mitchell J (2012) Childhood obesity: Can electronic medical records customized with clinical practice guidelines improve screening and diagnosis? J Am Acad Nurs Practitioners 24: 463- 471.

26. Hay WW, Levin JM, Sondheimer MJ, Deterding RR (2014) Current Diagnosis and Treatiment: Pediatrics. NewYork, NY: McGraw-Hill Education.

27. National Conference of State Legislatures [NCSL] (2014) Childhood obesity legislation: Twenty-thirteen update of policy options.

28. Boyer BP, Nelson JA, Holub SC (2015) Childhood body mass index trajectories predicting cardiovascular risk in adolescence. J Adolescent Health 56: 599-605.

29. Flores G, Hua L (2013) Factors predicting overweight in US kindergarteners. Am J Clin Nutr 97: 1178-1187.

30. Adair LS (2008) Child and adolescent obesity: Epidemiology and developmental perspectives. Physiology \& Behavior 94: 8-16.

31. Center for Disease Control [CDC] (2013) Use and interpretation of the WHO and CDC growth charts for children from birth to twenty years in the United States.

32. Center for Disease Control [CDC] (1998-2008) Obesity prevalenace among low-income preschool aged children United States.

33. Rolland-Cachera MF, Deheeger M, Maillot M, Bellisle F (2006) Early adiposity rebound: Cause and consequences for obesity in children. Int J Obes 30: 11-17.

34. Elley CR, Hoare K (2010) Working in primary care, in Preventing Childhood Obesity: Evidence, Policy, and Practice E. Waters, et al. Wiley-Blackwell: Hoboken, NJ.

35. Burton-Shepherd A (2015)How to recognize obesity in children. Practice Nursing, 26: 322-325.

36. MarenoN (2014) Parental perception of child weight: A concept analysis. J Adv Nurs 70: 34-45.

37. Camp NL (2014) Childhood healthy behaviors intervention in a pediatric primary care setting. Impact on provider practice $1-145$.

38. Schetchikova N (2009) A losing proposition: In the fight against the growing epidemic of childhood obesity, healthcare providers turn to novel approaches. American Chiropractic Association 5: 24-26.

39. Findholt NE, Davis MM, Michael YL (2013) Perceived barriers, resources, and training needs of rural primary care providers relevant to the management of childhood obesity. J Rural Health 29: $17-24$.

40. Daniels SR, Hassink SG (2015) The role of the pediatrician in primary prevention of obesity. Pediatrics 136: e275-e292.

41. Ho M, Garnett SP, Baur L, Burrows T, Stewart L, et al. (2012) Effectiveness of lifestyle interventions in child obesity: Systematic review with meta-analysis. Pediatrics 130: 16471671 .

42. Welsh JA, Nelson JM, Walsh S, Sealer H, Palmer W, et al. (2015) Brief training in patient-centered counseling for healthy weight management increases counseling self-efficacy and goal setting among pediatric primary care providers: Results of a pilot program. Clinical Pediatrics 54: 425-429.

43. Clark HR, Goyder E, Bissell P, Blank L, Peters J, et al. (2007) How do parents' child-feeding behaviours influence child weight? Implications for childhood obesity policy. J Pub Health 29: 132-141. 
44. Camp NL (2014) Childhood healthy behaviors intervention in a pediatric primary care setting: Impact on provider practice. Catholic University of America $159-159$

45. Boots SB, Tiggemann M, Corsini N, Mattiske J (2015) Managing young children's snack food intake: The role of parenting style and feeding strategies. Appetite 92: 94-101

46. Steffen LM, Sinaiko AR, Zhou X, Moran A, Jacobs Jr RD, et al. (2013) Relation of adiposity, television and screen time in offspring to their parents. BMC Pediatrics 13: 133-133.

47. Yuan WL, Rigal N, Monnery-Patris S, Chabanet C, Forhan A, et al. (2016) Early determinants of food liking among 5y-old children: A longitudinal study from the EDEN mother-child cohort. Int J Behav Nutr Phys Activity 13.

48. Howard AJ, Mallan KM, Byrne R, Magarey A, Daniels LA (2012) Toddlers' food preferences: The impact of novel food exposure, maternal preferences and food neophobia. Appetite 59: 818-825.

49. Lindsay AC, Sussner KM, Kim J, Gortmaker S (2006) The role of parents in preventing childhood obesity. Future of Children 16: $169-186$

50. Birch LL,Ventura AK (2009) Preventing childhood obesity: What works? Int J Obes 33: 74-81.

51. Katz DL (2011) Unfattening our children: Forks over feet. Int J Obes 35: 33-37.

52. Gutin B (2011) Diet versus exercise for the prevention of pediatric obesity: The role of exercise. Int J Obes 35: 29-32.

53. The W. Edwards Deming Institute (2016) The plan, do, study, act (PDSA) cycle.

54. Minnesota Department of Health Quality Improvement Toolbox.

55. United States Census Bureau (2010) QuickFacts: Columbus, Georgia.

56. Strong4Life. Strong4life role model assessment.

57. Center for Disease Control (2000) 2 to 20 years: Girls stature for age and weight for age percentile.

58. Steffen LM, Sinaiko AR, Zhou X, Moran A, Jacobs Jr RD, et al. (2013) Relation of adiposity, television and screen time in offspring to their parents. BMC Pediatrics. 13: 133-133.

59. Gordis L, Epidemiology (5th ed.) 2014, Philadelphia, PA: Elsevier. 


\section{Appendix A \\ Georgia State University \\ Department of Nursing \\ Informed Consent/Parental Permission}

Title: Childhood Obesity: Engaging Parental Role Modeling

Principal Investigator: Lee Eades, DNP, APRN, FNP-C

Student Principal Investigator: Gwendolyn Miller RN, MSN, FNP-C

\section{Purpose:}

You are the parent/guardian of a preschooler with a body mass index $>85 \%$ which makes you and the child (children) eligible for an invitation to participate in a research study. The purpose of the study is to provide par- ents of preschoolers with an interactive, familycenterededucational program to encourageengagement in their child's (children's) lifestyle goals and improveweight loss success. One hundred parent/child dyads for a total of 200 participantswill be recruited for this study. Participation in the study will require two hours of yours and your child's (children's) time over a six months period from August 1, 2016-March 30, 2017.

\section{Procedures:}

If you decide to participate, you will1) give your permission for the researchers to accessand evaluate your child's (children's) weight, height, and body mass index via the electronic medical record at Uptown Pediatrics prior to your child's (children's) scheduled office visit, as part of this study; 2) be asked by the researcher to fin- ish and turn in a pre-survey prior to thescheduled office visit today; 3) after the provider has finished the office visit, you will then be provided a ten minute educational in-service presented by the researcher; 4) then be asked to bring your child (children) back to Uptown Pediatrics three months after the in-service for a free weightmea- surement by the nurses 5) be given a post-survey by the researcher during the weight check to finish and turn in prior to leaving the office. At that time, the research will be finished.

\section{Risks:}

In this study, you and your child (children)will not have any more risks than you would in a normal day of life.

\section{Benefits:}

Participation in this study may benefit you and your child (children) by offering the knowledge of behaviors to apply at home to achieve and keep up a healthy weight.

\section{Voluntary Participation and Withdrawal:}

Participation is voluntary. You and your child (children) do not have to be in this study. Both you and your child (children) maintain the right to drop outof this study at any time during the study. You and your child (children) may skip questions or exit the in-service if you chose. Whatever your decision towardsyours or your child's (children's) involvement in the study, your child (children)will not lose any medical treatments that they are otherwise entitled.

\section{Confidentiality:}

We will keep your records private to the extent allowed by law. Permission may be withdrawn at any time. Lee Eades and Gwendolyn Miller are the principal investigators in this study and will have direct access to your surveys and your child's (children's) personal health information (weight, height, and body mass index) in this study. Information may also be shared with those who make sure the study is done correctly (GSU Institutional Review Board, the Office for Human Research Protection (OHRP). Your name or your child's (children's) name and other facts that might identify study participants will not appear when we present this study or publish its results. The findings will be summarized and reported in group form. You or your child (children) will not be identified personally.

The personal health information used during the study will be your child's (children's) pre and post height, weight, and body mass index. Personal health information used will be collected from the child's (children's) electronic health chart by the researcher Gwendolyn Miller who is granted access through a secured username and password. The informed consents will have yours and your child's (children's) names on them. However once obtained, the informed consentwill be kept in a locked drawer at Uptown Pediatrics that only the researcher Gwendolyn Miller will have the key to access.In addition, the surveys and the children's health data (weight, height, and body mass index) will not have any identifying information on them; this information will have a co- inciding chart number.A code sheet connecting the chart numbers with children's names will be kept separately from the data, in another locked drawer that only the researcher Gwendolyn Miller will have access to.

Your signature consentsto the use of your survey and your child's (children's) personal healthinformation until the end of the study. You have the right to request the information to not be used after it has been collected. To refuse use of surveys and personal health information after collection, write a letter of the request addressed to the attention of Gwendolyn Millerat 104 14th Street, Columbus, Georgia, 31901.

The surveys or health information offered during the research may not be reviewed by you until the end of the study. You may request a copy of the study to be sent to you after it is done.

\section{Contact Persons:}

Contact at Lee Eades phone- 404-413-1209 email- leades@gsu.edu and Gwendolyn Miller phone-706-587-8468 email-miller_gwendolyn@ columbusstate.edu if you have questions, concerns, or complaints. Call Susan Vogtner in the Georgia State University Office of Research Integrity at 404-413-3513 or svogtner1@gsu.edu to talk to someone not part of the study team. Susan Vogtner can offer guidance with general research questions, study complaints, or offer assistance if rights have been violated.

\section{Copy of Consent Form to Participant:}

A copy of the consent form will be provided for your records. 
If you are willing to volunteer for this research, and give your permission for your child (children) to participate, please sign below.

Child's Name

Child's Name

Child's Name

Participant

Principal Investigator or Researcher Obtaining Consent
Date

Date

Date

Date

Date

\section{Parental Role Model Assessment}

Place an $\mathrm{X}$ by the answer that best describes your eating and activity habits.

\begin{tabular}{|c|c|c|c|}
\hline & $\begin{array}{l}\text { Always/most } \\
\text { of the time }\end{array}$ & $\begin{array}{l}\text { About half } \\
\text { the time }\end{array}$ & $\begin{array}{l}\text { Very linter } \\
\text { not at all }\end{array}$ \\
\hline \multicolumn{4}{|l|}{ I eat vegetables, fruits and whole grains. } \\
\hline \multicolumn{4}{|l|}{$\begin{array}{l}\text { I drink water or low-fat milk, rather than soft drinks } \\
\text { or other sugar-sweetened beverages (for example, } \\
\text { sports drinks and fruit juices). }\end{array}$} \\
\hline \multicolumn{4}{|l|}{ I schedule family meals. } \\
\hline \multicolumn{4}{|l|}{ My children are involved in the grocery shopping. } \\
\hline \multicolumn{4}{|l|}{$\begin{array}{l}\text { I plan our family meals ahead of time (for example, } \\
\text { one week at a time). }\end{array}$} \\
\hline \multicolumn{4}{|l|}{$\begin{array}{l}\text { I make sure our family meal time is enjoyable, } \\
\text { by talking and asking questions of each other. }\end{array}$} \\
\hline \multicolumn{4}{|l|}{$\begin{array}{l}\text { I engage in at least } 30 \text { minutes of moderate } \\
\text { physical activity each day. }\end{array}$} \\
\hline \multicolumn{4}{|l|}{$\begin{array}{l}\text { I am active in front of my child or speak about } \\
\text { my activity in front of my child. }\end{array}$} \\
\hline \multicolumn{4}{|l|}{$\begin{array}{l}\text { I express a positive attitude about being } \\
\text { physically active. }\end{array}$} \\
\hline \multicolumn{4}{|l|}{$\begin{array}{l}\text { I encourage my children to be active, rather than } \\
\text { watching TV or being on a computer. }\end{array}$} \\
\hline \multicolumn{4}{|l|}{ I plan family physical activity time each week. } \\
\hline TOTAL: & & & \\
\hline
\end{tabular}

Appendix B 


\section{Appendix C}

2 to 20 years: Girls

Stature-for-age and Weight-for-age percentiles

NAME

$\begin{array}{lllllllll}12 & 13 & 14 & 15 & 16 & 17 & 18 & 19 & 20\end{array}$

\begin{tabular}{|c|c|c|c|c|}
\hline \multicolumn{4}{|c|}{ Mothers Stature } & \multicolumn{4}{|c|}{ Fathers Stature } \\
\hline Date & Age & Woight & Stature & BM* $^{*}$ \\
\hline & & & & \\
\hline & & & & \\
\hline & & & & \\
\hline & & & & \\
\hline & & & & \\
\hline & & & & \\
\hline & & & & \\
\hline
\end{tabular}

E'T AGE (YEARS)

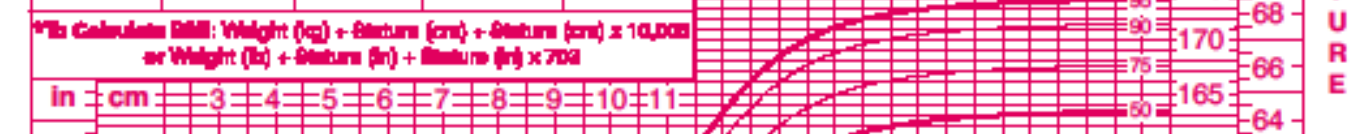

A$$
\text { (4. }
$$

E

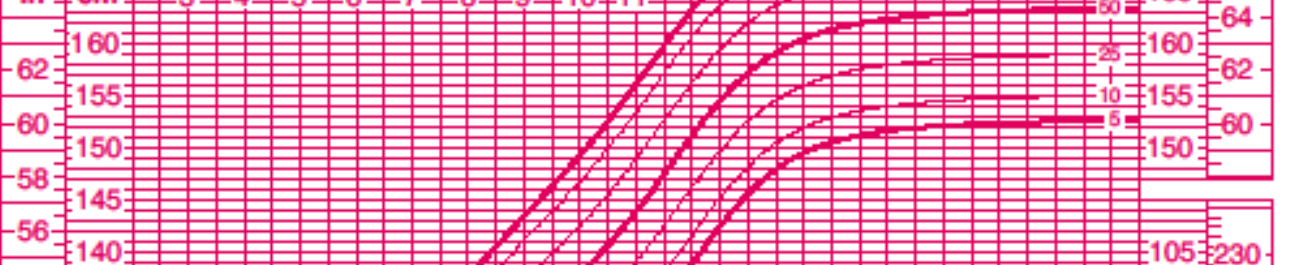

135

$-48$

$-48=120$

-46
-42

$$
-42
$$

$-42=105$

$$
-38=
$$

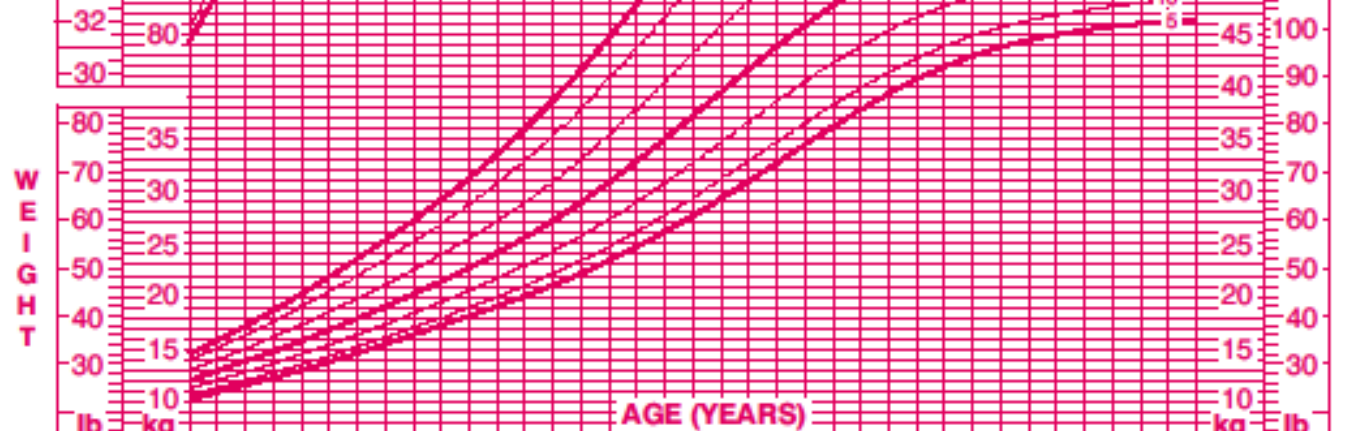

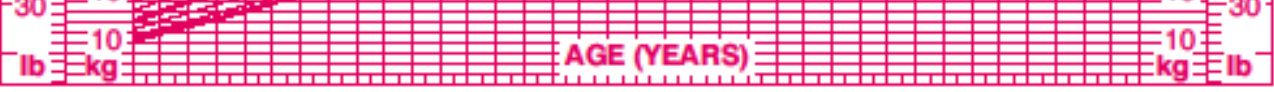
$\begin{array}{lllllllllllllllllll}2 & 3 & 4 & 5 & 6 & 7 & 8 & 9 & 10 & 11 & 12 & 13 & 14 & 15 & 16 & 17 & 18 & 19 & 20\end{array}$ Publestod Nay 30,2000 (modnad 11/21/00)

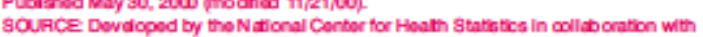

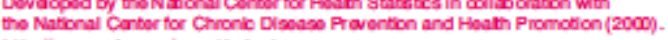

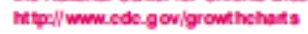

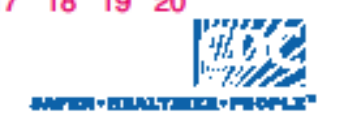




\section{Appendix D}

\begin{tabular}{|c|c|c|c|c|c|c|c|c|c|c|}
\hline Age & $\begin{array}{c}\text { Pre- } \\
\text { Survey }\end{array}$ & $\begin{array}{c}\text { Pre- } \\
\text { Height }\end{array}$ & $\begin{array}{c}\text { Pre- } \\
\text { Weight }\end{array}$ & $\begin{array}{c}\text { Pre-BMI } \\
\text { Individual }\end{array}$ & Pre-BMI & $\begin{array}{c}\text { Post- } \\
\text { Survey }\end{array}$ & $\begin{array}{c}\text { Post- } \\
\text { Height }\end{array}$ & $\begin{array}{c}\text { Post- } \\
\text { Weight }\end{array}$ & $\begin{array}{c}\text { Post-BMI } \\
\text { Individual }\end{array}$ & Post-BMI \\
\hline 3 & 17 & 37 & 36 & 18.5 & $96 \%$ & 18 & 38 & 39 & 19.0 & $97 \%$ \\
\hline 3 & 18 & 40 & 40.6 & 17.8 & $92 \%$ & 15 & 40 & 44 & 19.3 & $99 \%$ \\
\hline 5 & 17 & 46 & 66.5 & 22.1 & $99 \%$ & & & & & \\
\hline 2 & 15 & 36 & 39 & 21.2 & $99 \%$ & & & & & \\
\hline 3 & 18 & 39 & 41 & 19 & $99 \%$ & & & & & \\
\hline 3 & 11 & 40 & 45 & 19.8 & $99 \%$ & 11 & 41 & 46 & 18.3 & $95 \%$ \\
\hline 4 & 18 & 42 & 49 & 19.5 & $98 \%$ & & & & & \\
\hline 3 & 24 & 42 & 46 & 18.3 & $94 \%$ & 19 & 43 & 46 & 17.5 & $92 \%$ \\
\hline 2 & 24 & 36 & 35.25 & 19.1 & $97 \%$ & 18 & 38 & 36 & 20.9 & $98 \%$ \\
\hline 2 & 21 & 36 & 33 & 17.9 & $93 \%$ & 21 & 36 & 33 & 17.5 & $89 \%$ \\
\hline 3 & 16 & 35 & 31 & 17.8 & $92 \%$ & 13 & 36 & 33 & 17.9 & $93 \%$ \\
\hline 3 & 27 & 40 & 40 & 17.6 & $92 \%$ & 19 & 42 & 44 & 17.5 & $92 \%$ \\
\hline 2 & 13 & 40 & 40 & 17.6 & $89 \%$ & 14 & 42 & 41 & 17.6 & $89 \%$ \\
\hline
\end{tabular}

\section{Appendix E}

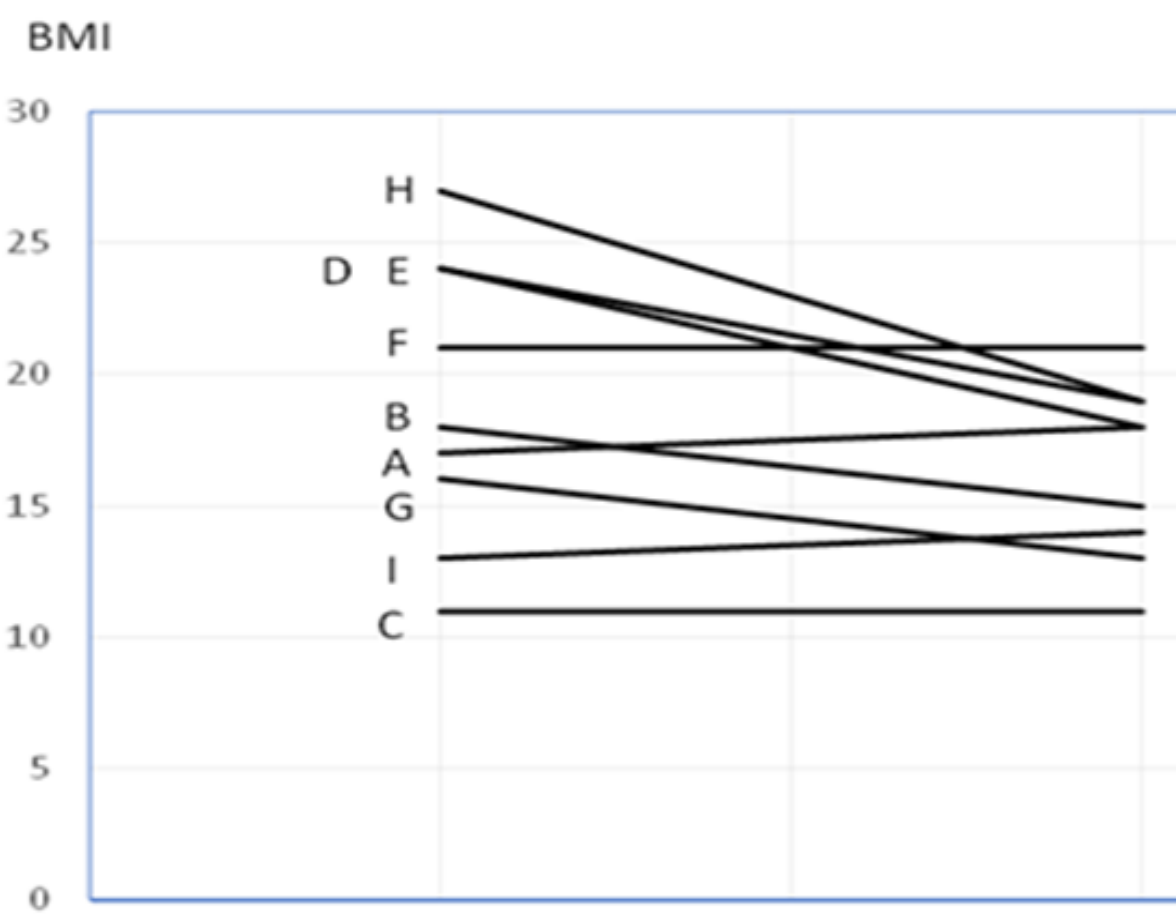

Pre-score

Post-score

Fig 1. Comparison of role modeling survey scores 